(C) Copyright 2020: Editum. Servicio de Publicaciones de la Universidad de Murcia. Murcia (Spain) ISSN print edition: 0212-9728. ISSN online edition (http://revistas.um.es/analesps): 1695-2294. Online edition License Creative Commons 4.0: BY-SA

\title{
Psychometric properties of the Spanish version of the Protective Factors of Resilience Scale (PFRS)
}

\author{
Eva León ${ }^{1}$, Marie-Carmen Neipp ${ }^{2 *}$, and Rosa María Nuñez ${ }^{1}$ \\ 1 Behavioural Science and Health Department, Miguel Hernandez University (Spain) \\ 2 Health Psychology Department, Miguel Hernandez University (Spain)
}

\begin{abstract}
Título: Propiedades psicométricas de la versión Española de la Escala de Factores Protectores de Resiliencia.

Resumen: Antecedentes: La resiliencia es la capacidad que tienen un individuo de recuperarse de las dificultades; la mayoría de las personas pueden recuperarse de forma óptima y adaptarse a eventos estresante a través de factores protectores. No existe, en español una medida válida y fiable de resiliencia que incluya tanto factores protectores interno como externos. El objetivo del estudio fue adaptar la escala Protective Factors of Resilience Scale al español y analizar sus propiedades psicométricas. Método: La escala fue traducida y adaptada al español y posteriormente se realizaron dos estudios para analizar sus propiedades psicométricas en dos muestras (personas sanas y con enfermedades crónicas). Los cuestionarios se enviaron por diferentes vías: email, Facebook y Whatsapp, 442 adultos completaron todos los cuestionarios. La muestra estuvo compuesta por 352 personas sanas y 90 con enfermedades crónicas. Resultados: En ambas muestras, los análisis de factores confirmatorios confirmaron la estructura de la escala, mostrando que la versión española estaba compuesta de tres factores. Las puntuaciones totales de la escala y de las subescalas mostraron una fiabilidad adecuada. La validez concurrente también se confirmó; la escala estuvo relacionada positivamente con diferentes medidas. Conclusión: Por tanto, la versión española de la escala es un instrumento fiable y válido para evaluar factores protectores (internos y externos) de la resiliencia tanto para población general como para personas con enfermedades crónicas.

Palabras clave: Cuestionario de resiliencia; Población española; Enfermedad; Factores protectores; Estudio instrumental.
\end{abstract}

\section{Introduction}

Resilience has been conceptualized in a multitude of ways, however, current views of resilience focus on the multidimensional nature of this construct, emphasizing that it is both dynamic and multi-systemic (Masten \& Narayan, 2012). Following Ungar (2013) resilience is viewed as the capacity of individuals to overcome adverse situations to navigate their way to the psychological, social, and physical resources that sustain their well-being. It is also studied even from a transcultural perspective (Coronado-Hijón, 2017). Recent studies report that, in situations where a disastrous event occurs, the way survivors cope with its consequences will depend both on external (community support) and internal resources (personal resistance) (Rahiem, Krauss, \& Rahim, 2018). In relation to the protective factors of resilience, they are considered to be made up both of individual characteristics (e.g., self-efficacy or personality traits) and external factors (e.g., interpersonal relationships and support level) that balance the risks to which individuals are exposed

* Correspondence address [Dirección para correspondencia]: Marie-Carmen Neipp. Health Psychology Department. Miguel Hernandez University. 03202. Elche, Alicante (Spain). E-mail: neipp@umh.es (Article received: 10-12-2019; revised: 09-01-2020; accepted: 10-03-2020)
Abstract: Background: Resilience is de capacity to recover from difficulties; most people can recover optimally from and adapt to stressful life events through the effect of protective factors. There is no valid and reliable measure of resilience in Spanish which includes both internal protective and external factors. Objective: The purpose of the present study was to adapt the Protective Factors of Resilience Scale (PFRS) to Spanish and to analyze its psychometric properties. Method: The scale was translated and adapted into Spanish, then, two studies were carried out to examine its psychometric properties in two samples (healthy and chronic illness). Questionnaires were sent by email, Facebook, and Whatsapp, and 442 adults completed all the questionnaires. The entire sample included 352 healthy people and 90 with a chronic illness. Results: In both samples, a second-order 3-factor model was the result of the exploratory factor analysis; the PFRS total and subscales scores showed adequate reliability. Concurrent validity was also studied; the PFRS was positively correlated with different measures. Conclusions: Therefore, the Spanish version of this scale is a reliable and valid instrument to assess protective factors (internal and external resources) of resilience both in Spanish general and chronically ill populations.

Keywords: Resilience questionnaire; Spanish population; Illness; Protective factors; Instrumental study.
(Rutter, 2012). Most people can recover optimally from and adapt to stressful life events through the effect of protective factors (Bolton, Praetorius, \& Smith-Osborne, 2016; Dias \& Cadime, 2017; Hamby, Grych \& Banyard, 2018).

Resilience assessment, both for the general population and for clinical populations, requires valid measuring instruments with good psychometric properties. In the review conducted by Windle, Bennett, and Noyes (2011), 15 instruments that assessed resilience were identified, but only three of them presented adequate psychometric properties; the other questionnaires had many deficiencies requiring additional validation. In addition, some studies of the measurement of resilience have found some inconsistencies between the risk factors and the protective processes of resilience (Luthar, Cicchetti, \& Becker, 2000). Protective factors contribute to individuals' good functioning despite the fact that exposure to stressful experiences could pose a significant risk for the development of a psychopathology (Hjemdal, Fribourg, Stiles, Rosenvinge, \& Martinussen, 2006). That is why Lee et al. (2013) believe that, to improve resilience, it is more effective to promote protective factors such as self-efficacy, positive affect, social support, or selfesteem than to reduce risk factors.

Despite the enormous importance of resilience for the individual, there are few instruments to measure it in Spanish 
that can be applied to both to the general and the clinical population. Among the resilience questionnaires adapted and validated in Spanish are the CD-RISC (Crespo, FernándezLansac, \& Soberón, 2014) and the BRS (Rodríguez-Rey, Alonso-Tapia, \& Hernansaiz-Garrido, 2016). The former evaluates a series of internal individual resources that facilitate recovery, such as personal competence or positive acceptance of change by the individual, among others. And the latter one assesses resilience as an outcome, that is, the ability to recover from a stressful event.

However, there is currently no valid and reliable measure of resilience that includes both internal protective and external factors and that can be applied to the general Spanish population (Dias \& Cadime, 2017). Drawing on research of the importance of protective factors in resilience, the Protective Factors for Resilience Scale (PFRS) (Harms, Pooley, \& Cohen, 2017) emerges. The authors used a sample of university students to study the factor structure of the scale and a second sample of the community population to confirm it. Different factorial models were analyzed, and authors concluded that, following the definition of resilience proposed by Pooley and Cohen (2010), the best one was that included a personal factor and two external factors related to family and peers; and due to the degree of association between the factors, an overarching construct was explained. Therefore, the factorial structure of the PFRS scale was the 3-ordersecond factor model. This scale consists of 15 items with a seven-point Likert response scale ranging from 1 (totally disagree) to 7 (totally agree). It presents a model with 3 subscales of five items each: Personal Resources (PR), Family Resources (SR-F), Peer Resources (SR-P). High scores indicate high resources on each of the subscales. The scale showed a high Cronbach alpha coefficient .93, moreover, relations between different variables (coping style, self-esteem and life satisfaction and the scores of the PFRS provided good evidence of the construct validity.

In cancer patients, Harms et al. (2019), have confirmed the same factorial structure, obtaining a Cronbach coefficient of .96 , a root mean square error of approximation [RMSEA] of .06; a comparative fit index [CFI] of .99; a standardized root mean square residual [SRMR] of .07; and a goodness-of-fit index [GFI] of .99. The PFRS questionnaire has not yet been validated in Spanish population and there is also no instrument of similar characteristics to assess resilience in this language. The progressive interest in resilience, both for the complexity of its construct and the factors that form it, requires scientific research to focus on the adaptation and reliable validation of instruments to evaluate it, given the protective effect of resilience in different populations (Cronly et al., 2019; Ellis, Bianchi, Griskevicius, \& Frankenhuis, 2017; Lee et al., 2017).

Therefore, our goal was to examine the factorial structure of the Protective Factors for Resilience Scale (PFSR) in two Spanish populations, community population and population with chronic disease (understood as long-term and usually slow-progressing diseases).

\section{Method}

\section{Procedure}

Back-translation of the questionnaire was carried out. Two studies were subsequently conducted. In the first study, the instrument was applied to a sample of Spanish community population; in the second study, it was applied to a sample of Spanish people with chronic diseases.

A bilingual translator translated the PFRS from English to Spanish. Two psychologists of the team independently reviewed the translation, then agreeing by consensus on a final version. Lastly, this version was back-translated from Spanish to English by another bilingual psychologist to ensure the equivalence of the translation. Table 1 contains the final Spanish adaptation of the PFSR.

A snowball sampling was used to gather data from December 2018 to February 2019, through digital internet questionnaires. Questionnaires were sent by email, Facebook, Whatsapp asking people fill them in and to send them to their relatives or friends to also be filled in. Finally, 352 healthy individuals and 90 individuals with chronic illness completed all the questionnaires. This research project was approved by the Ethics Committee of the university.

\section{Instruments}

The main sociodemographic data (age, sex, marital status, employment, educational level) were collected, and we asked participants whether they had any chronic diseases and, if so, the diagnosis. The following instruments were applied in both samples:

The Brief Resilience Scale-BRS, developed by Smith et al. (2008). This study used the Spanish validation (RodríguezRey, Alonso-Tapia, \& Hernansaiz-Garrido, 2016). The goal of this scale is to measure people's resilience to stress. It consists of 6 items with a five-point Likert response scale ranging from 1 (totally disagree) to 5 (totally agree). High scores indicate a high degree of resilience; the coefficient of internal consistency was .84 for the Spanish community sample and .88 in the Spanish sample of chronically ill people.

The Rosenberg Self-Esteem Scale (RSE). This instrument was originally developed by Rosenberg (1965). The Spanish version and adaptation was developed by Vázquez, GarcíaBóveda, and Vázquez-Morejón (2004). This scale consists of 10 items rated on a four-point Likert scale ranging from 1 (strongly disagree) to 4 (strongly agree). Five items are negatively worded and five are positively worded, obtaining a total score by adding all the items, and reversing the negative statements. In the Spanish community sample, the Cronbach alpha coefficient was .86, and in the Spanish sample of chronically ill, it was .82 .

Ryff's Psychological Wellbeing Scales (PWB). Ryff's original version consists of 120 items and has an internal consistency of .84 (Ryff, 1989). For this group, the Spanish version validated by Díaz et al. (2006). was used. It consists of 39 items 
rated on a 6-point Likert scale ranging from 1 (totally disagree) to 6 (totally agree). The total score ranges from 122 (low psychological well-being) to 152 (high psychological well-being). The items in this questionnaire are grouped into 6 subscales that measure Self-Acceptance, Positive Relationships with others, Autonomy, Environmental Mastery, Purpose in Life, and Personal Growth. Both in the Spanish community sample and in the sample of chronically ill people, the internal consistency coefficients of the subscales ranged from .42 to .85. The overall score obtained a Cronbach alpha coefficient of .90 in both samples.

The Life Orientation Test - Revised (LOT-R); the revised version of the LOT (Scheier, Carver, \& Bridges, 1994). In this study, we used the Spanish version of the LOT-R developed by Otero, Luengo, Romero, Gómez, and Castro (1998). The questionnaire consists of 10 items rated on a five-point Likert scale ranging from 1 (totally disagree) to 5 (totally agree). The dimension of dispositional optimism is evaluated with 6 items, the remaining 4 items are considered "fillers" and are intended to make the content of the test less evident. Of the 6 content items, 3 of them are worded positively (direction of optimism [O]) and 3 negatively (direction of pessimism $[\mathrm{P}])$. In the community population sample, the Cronbach alpha coefficient for LOT-O was .76, and for LOT-P, it was .64. In the sample with chronically ill people, the coefficients were .80 and .69 for the Optimism and Pessimism scales, respectively.

\section{Data analysis}

The same statistical analyses were performed in both studies. The SPSS version 25.0 was used for the descriptive study of the sample, and Exploratory Factorial Analysis (EFA) was performed with Factor 10.10.01 (Lorenzo-Seva \& Ferrando, 2006); the extraction method used was unweighted least squares method (ULS) with Promin rotation (Lorenzo-Seva, 1999) and Optimal Implementation of Parallel Analysis (Timmerman \& Lorenzo-Seva, 2011) to decide the number of factors. The goodness of fit of the data to the model it was evaluated with the percentage of total variance explained by the factors and the following indices and reference values: Goodness-of-Fit Index (GFI) equal to or great- er than .95 (Miles \& Shevlin, 1998) and Root Mean Square of Residuals (RMSR) equal to or less than .08 (Hu \& Bentler, 1999).

\section{Results}

\section{Study 1}

The sample consisted of 352 people aged between 16 and 83 (mean age 34.46, SD $=13.29$ years), 56.5\% living in the province of Alicante, and $43.5 \%$ in other provinces. Of these, $67.6 \%$ were women; $0.3 \%$ stated that they had no studies, $2.8 \%$ had primary or similar studies, $25.3 \%$ had secondary, high school or similar studies, and $71.6 \%$ had university studies. Concerning marital status, $62.2 \%$ were single, $28.1 \%$ were married or living as a couple, $9.4 \%$ were separated or divorced, and $0.3 \%$ were widowed. In terms of their work activity, $0.6 \%$ were engaged in housework, $38.6 \%$ were students, $55.7 \%$ were employed, $2.8 \%$ were unemployed, and $2.3 \%$ were retired. All participants stated that they were not diagnosed with any disease.

\section{Construct V alidity}

The measures $\mathrm{KMO}=.82$ and Bartlett's statistic $=$ $2738.6(\mathrm{df}=105, \mathrm{p}<.001)$ indicated that the matrix is suitable for factoring. Parallel Analysis recommended the extraction of three factors. The model fit indices were GFI $=.99$ and RMSR $=.039$, values that indicate the fit of the data to the model. The 3 -factor solution explained $68.84 \%$ of the total variance (factor 1 explained $41.18 \%$, factor 2 explained $14.27 \%$ and factor 3 explained $13.39 \%$ of the variance). Table 1 shows the rotated loading matrix and communalities, all items were factor loading greater .40. Items which assess social resources family (SR-F) loaded onto factor 1, items which assess social resources peers (SR-P) loaded onto factor 2 and items which assess personal resources (PR) loaded onto factor 3. Correlations between the three factors were: SR-F and SR-P was .492, SR-F and PR was .427, and SR-P and PR was .391; these values suggest the presence of a second order.

Table 1. Factor loadings and communality of the 15 items of PFRS

\begin{tabular}{|c|c|c|c|c|c|c|c|c|}
\hline & \multicolumn{4}{|c|}{ Community sample } & \multicolumn{4}{|c|}{ Chronic patients } \\
\hline & $\overline{\text { SR-F }}$ & SR-P & PR & $\mathrm{h}^{2}$ & SR-F & SR-P & $\begin{array}{l}\text { PR } \\
\text {. }\end{array}$ & $\mathrm{h}^{2}$ \\
\hline \multicolumn{9}{|l|}{ SR-F: Social Resources Family } \\
\hline $\begin{array}{l}\text { i4. My family are a source of strength for me } \\
\text { (Mi familia es una fuente de fortaleza para mî) }\end{array}$ & .863 & & & .67 & .845 & & & .69 \\
\hline $\begin{array}{l}\text { i8. I feel accepted by my family } \\
\text { (Me siento aceptado/a por mi familia) }\end{array}$ & .848 & & & .75 & .836 & & & .73 \\
\hline $\begin{array}{l}\text { i10. I know that my family would help me if I needed help } \\
\text { (Sé que mi familia me ayudaría si necesitara ayuda) }\end{array}$ & .798 & & & .74 & .574 & & & .64 \\
\hline $\begin{array}{l}\text { i12. I feel comfortable around my family } \\
\text { (Me siento cómodo/a con mi familia) }\end{array}$ & .923 & & & .82 & .906 & & & .74 \\
\hline $\begin{array}{l}\text { 115. I feel safe within my family } \\
\text { (Me siento seguro/a en mi familia) }\end{array}$ & .930 & & & .87 & .944 & & & .79 \\
\hline
\end{tabular}




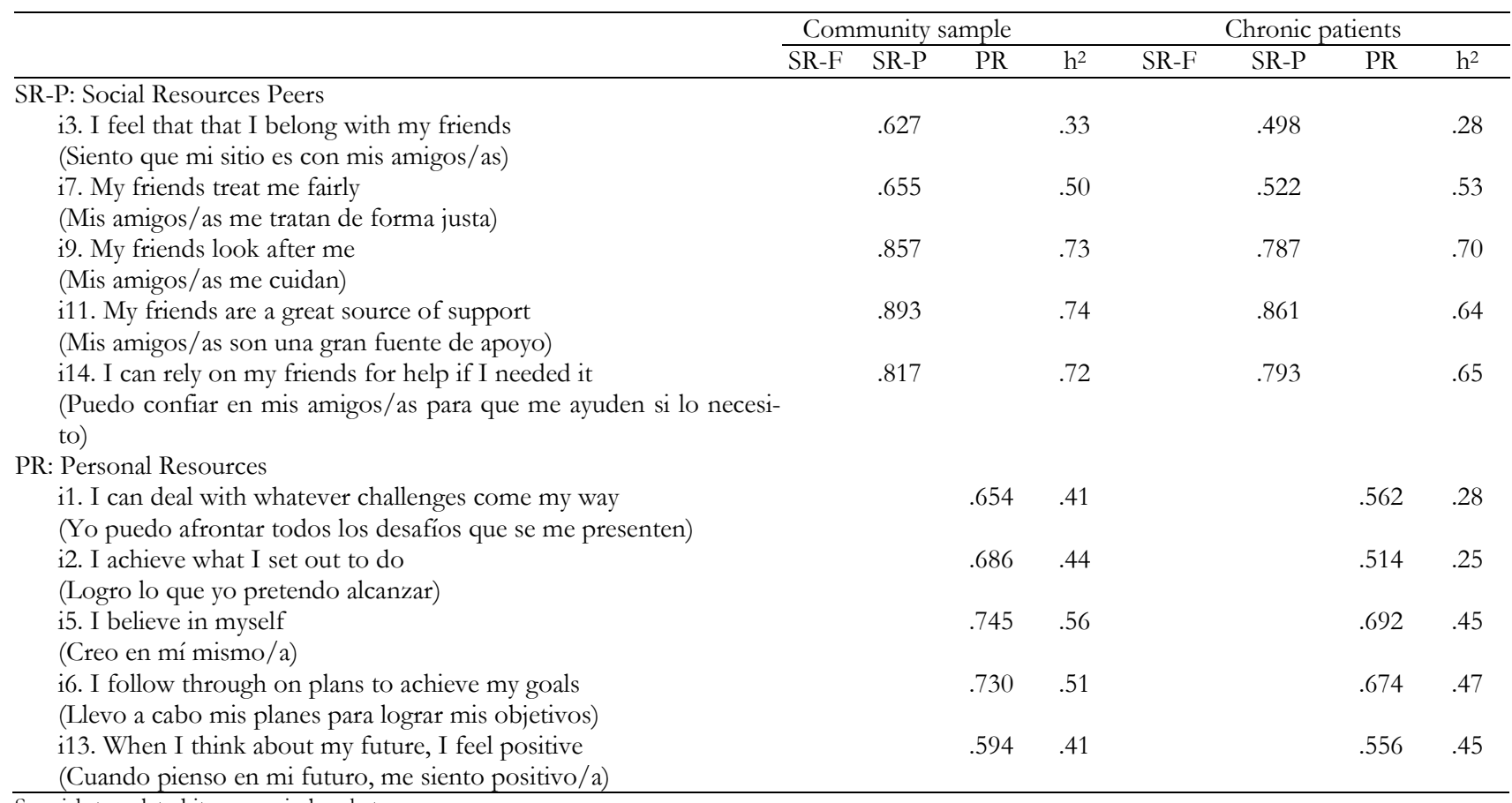

Spanish translated items are in brackets.

\section{Analysis of Internal Consistency}

Table 2 shows the values of internal consistency, mean score, standard deviation, minimum and maximum PFRS score, and the subscales in this general population sample. All scores showed adequate internal consistency both in the total scale and the factor scores.

Table 2. Internal consistency, standard deviations, minimum and maximum in both samples' Spanish general chronic patients

\begin{tabular}{|c|c|c|c|c|c|c|}
\hline & \multicolumn{2}{|c|}{ Cronbach Alpha } & \multicolumn{2}{|c|}{ Mean $(S D)$} & \multicolumn{2}{|c|}{ Min.-Max. } \\
\hline & General & Patients & General & Patients & General & Patients \\
\hline FPRS & .81 & .85 & $89.08(8.24)$ & $87.43(9.91)$ & $66-105$ & $60-104$ \\
\hline SR-F & .90 & .90 & $31.97(4.04)$ & $31.67(4.82)$ & $17-35$ & $11-35$ \\
\hline SR-P & .84 & .87 & $29.26(4.13)$ & $28.48(4.99)$ & $15-35$ & $9-35$ \\
\hline PR & .78 & .77 & $27.85(4.05)$ & $27.29(4.15)$ & $15-35$ & $13-34$ \\
\hline
\end{tabular}

FPRS: Protective Factor for Resilience Scale; SR-F: Social Resources Family; SR-P: Social Resources Peers; PR: Personal Resources

\section{Concurrent and convergent validity}

Table 3 shows the correlations between the PFRS and the other instruments applied in the sample. All correlations were positive except for those that related resilience and pessimism (assessed with LOT-P), which were negative. The highest correlations were between the total PFRS score and its PR subscale with the Optimism subscale (LOT-R), SelfEsteem, the total Ryff score and its subscales, especially the correlations with Self-Acceptance, Environmental Mastery, and Purpose in Life. The SR-P subscale had the highest correlation with the Ryff Positive Relationships subscale. The correlation between the PR subscale and the BRS was also high and significant. Therefore, this scale shows adequate evidence of convergent and concurrent validity.
Table 3. Pearson's correlations between FPRS, the three factors and other instruments.

\begin{tabular}{lcccc}
\hline & FPRS & SR-F & SR-P & PR \\
\hline LOT-O & $.385^{* *}$ & .088 & .063 & $.577^{* *}$ \\
LOT-P & $-.334^{* *}$ & -.080 & $-.109^{*}$ & $-.487^{* *}$ \\
Self-esteem & $.464^{* *}$ & $.211^{* *}$ & .094 & $.638^{* *}$ \\
PWB Total & $.606^{* *}$ & $.252^{* *}$ & $.301^{* *}$ & $.674^{* *}$ \\
PWB-Self-acceptance & $.547^{* *}$ & $.263^{* *}$ & $.180^{* *}$ & $.666^{* *}$ \\
PWB-Positive Relations & $.510^{* *}$ & $.201^{* *}$ & $.607^{* *}$ & $.217^{* *}$ \\
PWB-Autonmy & $.310^{* *}$ & $.123^{*}$ & .066 & $.442^{* *}$ \\
PWB-Enviromental mastery & $.469^{* *}$ & $.227^{* *}$ & $.135^{*}$ & $.589^{* *}$ \\
PWB-Personal Growth & $.329^{* *}$ & .083 & $.174^{* *}$ & $.409^{* *}$ \\
PWB-Purpose in life & $.513^{* *}$ & $.216^{* *}$ & $.146^{* *}$ & $.679^{* *}$ \\
BRS & $.336^{* *}$ & .067 & .097 & $.518^{* *}$ \\
\hline
\end{tabular}

FPRS: Protective Factor for Resilience Scale; SR-F: Social Resources Family; SR-P: Social Resources Peers; PR: Personal Resources; LOT-O: Life Orientation Test-Optimism; LOT-P: Life Orientation Test-Pessimism; PWB: Ryff's Psychological Well-Being Scale; BRS; Brief Resilience Scale 


\section{Study 2}

The sample consisted of 90 people with chronic diseases; their ages ranged from 17 to 77 years (mean 39.97, SD = 15.40 years); $47.8 \%$ resided in the province of Alicante, and $52.2 \%$ in other provinces. Of these, $75.6 \%$ were; $2.2 \%$ had primary or similar studies, $35.6 \%$ had secondary, high school or similar studies, and $62.2 \%$ had university studies. Regarding marital status, $48.9 \%$ were single, $44.4 \%$ were married or living as a couple, $6.7 \%$ were separated or divorced. In terms of their work activity, $4.4 \%$ were engaged in housework, $26.7 \%$ were students, $53.3 \%$ were employed, $4.4 \%$ were unemployed, and $11.1 \%$ were retired. All participants reported having a chronic diagnosed disease: $17.8 \%$ a rheumatic disease, $16.7 \%$ a circulatory system disease, $15.6 \%$ an endocrine system disease, $11.1 \%$ a digestive system disease, $11.1 \%$ a respiratory system disease, $7.8 \%$ a neurological disease, $6.7 \%$ suffered from some type of allergy, 4.4\% a gynecological disease, $1.1 \%$ urological disease, $1.1 \%$ oncological disease, $1.1 \%$ hematological disease, and $5.6 \%$ did not indicate the type of disease.

\section{Construct Validity}

The measures KMO $=.80$ and Bartlett's statistic $=991.4$ $(\mathrm{df}=105, p<.001)$ indicated that the matrix is suitable for factoring. The model fit indices were GFI $=1.00$ and RMSR $=.033$, values that indicate the fit of the data to the model. The 3-factor solution from Harms, Pooley and Cohen model (2017) was checked. Parallel Analysis recommended the extraction of one or two factors.

The 3-factor solution explained $63.82 \%$ of the total variance (factor 1 explained $42.60 \%$, factor 2 explained $11.76 \%$ and factor 3 explained $9.45 \%$ of the variance). Table 1 shows the rotated loading matrix and communality, all items were factor loading greater .40. Items which assess social resources family (SR-F) loaded onto factor 1, items which assess social resources peers (SR-P) loaded onto factor 2 and items which assess personal resources (PR) loaded onto factor 3. Correlations between the three factors were: SR-F and SR-P was .601, SR-F and PR was .529, and SR-P and PR was .547 ; these values suggest the presence of a second order.

\section{Analysis of Internal Consistency}

Table 2 shows the values of internal consistency, mean score, standard deviation, and minimum and maximum score. As in the general sample, in the Spanish sample of chronically ill patients, the internal consistency coefficients of the total scale and of the three factors were good.

\section{Concurrent and convergent validity}

Table 4 shows the correlations between the PFRS and the other instruments applied in the sample. As in the com- munity sample, the correlations between global score of PFRS and Pessimism (assessed with LOT-P) was negative. The positive and statistically significant correlation coefficients ranged from .228 , between the PR subscale and Ryff's Positive Relationships with others, to .697 , between PR and Self-esteem.

Table 4. Pearson's correlations between FPRS, the three factors and other instruments.

\begin{tabular}{lcccc}
\hline & FPRS & SR-F & SR-P & PR \\
\hline LOT-O & $.412^{* *}$ & .125 & .200 & $.598^{* *}$ \\
LOT-P & $-.284^{* *}$ & -.092 & $-.210^{*}$ & $-.320^{* *}$ \\
Self-esteem & $.477^{* *}$ & $.230^{*}$ & .147 & $.697^{* *}$ \\
PWB Total & $.536^{* *}$ & $.275^{* *}$ & $.327^{* *}$ & $.565^{* *}$ \\
PWB-Self-acceptance & $.609^{* *}$ & $.308^{* *}$ & $.372^{* *}$ & $.649^{* *}$ \\
PWB-Positive Rela- & $.551^{* *}$ & $.313^{* *}$ & $.601^{* *}$ & $.228^{* *}$ \\
tions & .080 & .029 & -.072 & $.243^{*}$ \\
PWB-Autonmy & $.387^{* *}$ & .201 & .142 & $.519^{* *}$ \\
PWB-Enviromental & & & & \\
mastery & $.251^{*}$ & .106 & .182 & $.258^{*}$ \\
PWB-Personal & $.530^{* *}$ & $.271^{* *}$ & $.256^{* *}$ & $.642^{* *}$ \\
Growth & $.378^{* *}$ & .140 & .134 & $.580^{* *}$ \\
PWB-Purpose in life & BRS
\end{tabular}

FPRS: Protective Factor for Resilience Scale; SR-F: Social Resources Family; SR-P: Social Resources Peers; PR: Personal Resources; LOT-O: Life Orientation Test-Optimism; LOT-P: Life Orientation Test-Pessimism; PWB: Ryff's Psychological Well-Being Scale; BRS; Brief Resilience Scale

\section{Discussion}

The objective of this study was to verify the psychometric properties of the Spanish version of the Protective Factors for Resilience Scale in Spanish community population and in a Spanish population of chronically ill patients. The results suggest that the scores of the Spanish version have adequate psychometric properties, in terms of reliability and validity.

The data of the Spanish version, analyzed through Exploratory Factorial Analysis (AFE), maintain the same factorial structure as the original questionnaire in both samples, the second-order 3-factor model. The first-order factors were: two external factors (Family and Peer Resources) and one Personal Resources factor and the second-order factor, a total resilience score. The GFI and RMSR were above and under the cut-off points, respectively, it indicated a satisfactory goodness of fit. In the sample of chronic patients, the Parallel Analysis advised to reduce the number of dimensions from three-factor to two-factor. Therefore, a second AFE was performed on this sample. So, it turned out that the SR-F factor was maintained and the SR-P and PR factors were together into one. The correlation between these two factors defined a second-order 2-factor model. The goodness of fit of data to model and psychometric properties were satisfactory as well. Therefore, further research is need to investigate whether this factor structure is a result of the sample size (although the illness samples are usually not very large) and / or if the resilience in chronic patients is explained by other components than the general population. 
The analyses to assess the PFRS's concurrent and convergent validity show that the scale factors are related to the questionnaires that measure similar constructs in both populations. We note that the factor of Personal Resources has high positive relationships with the variables Optimism (LOT), Self-Esteem (RSE), the Ryff subscales of SelfAcceptance, Autonomy, Environmental Mastery, and Personal Growth, and lastly, with the Brief Resilience Scale. This is very consistent, as all these constructs refer to the person's individual resources, thus supporting the validity of this subscale. Also, the external factor of Peer Resources has a high relationship with the Ryff subscale of Positive Relationships, again confirming the construct, as both scales refer to the relationships that are established with other people. Finally, the overall scale score is also adequately related to all the other criterion variables.

These results have different implications. First, they provide a valid and reliable measure to evaluate both internal and external resources associated with resilience for application in Spanish population. In addition, the results also indicate that this scale could be used both in general and chronically ill populations. Also, this scale is much shorter than many scales that evaluate these factors (Windle, Bennett, \& Noyes, 2011) and may be much more attractive for use in different contexts, both clinical and non-clinical. However, more studies are needed, with larger samples of patients with different chronic diseases, to confirm the validity of the scale in different diseases and thus, for use in clinical settings.

This study also shows some limitations. The questionnaire was applied at a certain time without further applications, so the predictive validity of the scale could not be analyzed. The items of the PFRS are rated on a Likert format with seven alternatives. In both samples, the higher response categories (6 and 7) were the most frequently chosen in con-

\section{References}

Bolton, K. W., Praetorius, R. T., \& Smith-Osborne, A. (2016). Resilience Protective Factors in an Older Adult Population: A Qualitative Interpretive Meta-Synthesis. Social Work Research, 40(3), 171-182. https://doi.org/10.1093/swr/svw008

Coronado-Hijón, A, (2017). Academic Resilience: A Transcultural Perspective. Procedia - Social and Behavioral Sciences, 237, 594-598. https://doi.org/10.1016/j.sbspro.2017.02.013

Crespo, M., Fernández-Lansac, V., \& Soberón, C. (2014). Adaptación española de la "Escala de Resiliencia de Connor-Davidson" (CD-RISC) en situaciones de estrés Crónico [Spanish adaptation of the "ConnorDavidson Resilience Scale" (CD-RISC) in situations of Chronic stress]. Behavioral Psychology, 22(2), 219-238.

Cronly, J., Duff, A., Riekert, K., Horgan, A., Lehane, E., Perry, I., Fitzgerald, A., Howe, B., Chroinin, M., \& Savage, E. (2019). Positive mental health and wellbeing in adults with cystic fibrosis: A cross sectional study, Journal of Psychosomatic Research, (116), 125-130. https://doi.org/10.1016/j.jpsychores.2018.11.016

Ellis, B. J., Bianchi, J. M., Griskevicius, V., \& Frankenhuis, W. E. (2017). Beyond Risk and Protective Factors: An Adaptation-Based Approach to Resilience. Perspective on Psychological Science, 12(4), 561-587. https://doi.org/10.1177/1745691617693054 trast to the lower ones (1 and 2) with very low frequencies, which could lead to a bias in the results. This choice homogeneity could also be affecting the reliability and validity of the scale. It would therefore be interesting to conduct another study to reduce the number of response alternatives from seven to five to determine whether the asymmetry in the choice of responses decreases. Moreover, it has been found that by increasing the number of response categories in Likert scales, reliability improves (Lozano, García-Cueto, \& Muñiz, 2008), but when this number exceeds four or five alternatives, reliability does not improve substantially. Therefore, due to the response homogeneity observed in this study and the empirical evidence of the most adequate number of categories to improve the psychometric properties of a scale, a goal for further research would be to study the factorial structure of the scale by reducing the number of response alternatives to five.

In conclusion, the findings of this study support the plausibility of a second-order 3-factor model of the PFRS, and this structure is maintained in both general and chronic Spanish population. Moreover, due to the quality of the psychometric properties of the scale and its brevity, it is preferable to other measures that are currently available for the Spanish population. Nevertheless, it would be necessary to extend this work with sensitivity and specificity studies to support the use of this scale in both samples.

Funding Source: This research received no specific grant from any funding agency in the public, commercial, or not-for-profit sectors.

Acknowledgements.- The authors would like to thank all the participants involved in this study.

Dias, P. C., \& Cadime, I. (2017). Protective factors and resilience in adolescents: The mediating role of self-regulation. Psicología Educativa, 23(1), 37-43. https://doi.org/10.1016/j.pse.2016.09.003

Díaz, D., Rodríguez-Carvajal, R., Blanco, A., Moreno-Jiménez, B., Gallardo, I., Valle, C. \& Dierendonck, D. V. (2006). Adaptación española de las escalas de bienestar psicológico de Ryff [Spanish adaptation of Ryff's psychological well-being scales]. Psicothema, 18(3), 572-577.

Hamby, S., Grych, J., \& Banyard, V. (2018). Resilience portfolios and polystrengths: Identifying protective factors associated with thriving after adversity. Psychology of Violence, $8(2), \quad 172-183$. http://dx.doi.org/10.1037/vio0000135

Harms, C., Pooley, J.A., \& Cohen, L. (2017). The protective factors for resilience scale (PFRS): Development of the scale. Cogent Psychology, 4, 1400415. https://doi.org/10.1080/23311908.2017.1400415

Harms, C., Cohen, L., Pooley, J.A., Chambers, S., Galvão, D., \& Newton, R. (2019). Quality of life and psychological distress in cancer survivors: The role of psycho-social resources for resilience. Psycho-Oncology, 28, 271-277. https://doi.org/10.1002.pon.4934

Hjemdal, O., Friborg, O., Stiles, T. C., Rosenvinge, J. H., \& Martinussen, M. (2006). Resilience predicting psychiatric symptoms: A prospective study of protective factors and their role in adjustment to stressful life events. Clinical Psychology and Psychotherapy, 13, 194-201. https://doi.org/10.1002/ 
Hu, L., \& Bentler, P.M. (1999). Cutoff criteria for fit indexes in covariance structure analysis: Conventional criteria versus new alternatives. Structural Equation Modeling: A Multidisciplinary Journal, 6, 1-55, https://doi.org/10.1080/10705519909540118

Lee J. H., Nam, S. K., Kim, A. R., Kim, B., Lee, M. Y., \& Lee, S. M. (2013). Resilience: a meta-analytic approach. Journal of Counseling Development, 91, 269-279. https://doi.org/10.1002/j.1556-6676.2013.00095.x

Lee, D., Boseok, C., Chul-Soo, P., Bong-Jo, K., Cheol-Soon, L., So-Jin, L., Ji-Yeong, S., Young, A.C., Jong, H., Jong, H.H., \& Jae-Won, C. (2017). Effects of resilience on quality of life in patients with bipolar disorder. Journal of Affective Disorders, 207, 434-441. https://doi.org/10.1016/j.jad.2016.08.075

Lorenzo-Seva, U. (1999). Promin: a method for oblique factor rotation. Multivariate Behavioral Research, 34, 347-365. https://doi.org/10.1207/S15327906MBR3403_3

Lorenzo-Seva, U. \& Ferrando, P. J. (2006). FACTOR: a computer program to fit the exploratory Factor Analysis model. Behavioral Research Methods, $38,88-91$.

Lozano, L. M., García-Cueto, E., \& Muñiz, J. (2008) Effect of the number of response categories on the reliability and validity of rating scales. Methodology, 4, 73-79. https://doi.org/10.1027/1614-2241.4.2.73

Luthar, S., Cicchetti, D., \& Becker, B. (2000). The Construct of Resilience: A Critical Evaluation and Guidelines for Future Work. Child Development, 71(3), 543-562. https://doi.org/10.1111/1467-8624.00164

Masten, A. S., \& Narayan, A. J. (2012) Child development in the context of disaster, war, and terrorism: Pathways of risk and resilience. Annual Review of Psychology, 63(1), 227-257.

Miles, J. \& Shevlin, M. (1998). Effects of sample size, model specification and factor loadings on the GFI in confirmatory factor analysis, Personality and Individual Differences, 25, 85-90.

Otero, J. M., Luengo, A., Romero, E. Gómez, J. A. \& Castro, C. (1998). Psicología de personalidad. Manual de prácticas Personality psychology. Practice Manual]. Barcelona: Ariel Practicum.

Pooley, J., \& Cohen, L. (2010). Resilience: A Definition in Context. Australian Community Psychologist, 22, 30-37.

Rahiem, H. M. D., Krauss, S. E., \& Rahim, H. (2018). The Child Victims of the Aceh Tsunami: Stories of Resilience, Coping and Moving on with
Life. Procedia Engineering, 212, 1303-1310. https://doi.org/10.1016/j.proeng.2018.01.168

Ryff, C. (1989). Beyond Ponce de Leon and life satisfaction: New directions in quest of successful aging. International Journal of Behavioral Development, 12, 35-55. https://doi.org/10.1177/016502548901200102

Rodríguez-Rey, T., Alonso-Tapia, J. \& Hernansaiz-Garrido, H. (2016). Reliability and Validty of the Brief Resilience Scale (BRS) Spanish Version. Psychological Assessment, 26(5), e101-e110. http://dx.doi.org/10.1037/pas0000191

Rosenberg, M. (1965). Society and the adolescent self-image. Editorial Princenton. University Press. Princenton.

Rutter, M. (2012). Resilience as a dynamic concept. Development and Psychopathology, 24(2), 335-344. doi: https://doi.org/10.1017/S0954579412000028

Scheier, M. F. L., Carver, C.S., \& Bridges, M. W. (1994). Distinguishing optimism from neuroticism (and trait anxiety, self-mastery, and selfesteem): a reevaluation of the Life Orientation Test. Journal of Personality and Social Psychology, 67(6), 1063-78.

Smith, B. W., Dalen, J., Wiggins, K., Tooley, E., Christopher, P., \& Bernard, J. (2008). The Brief Resilience Scale: Assessing the Ability to Bounce Back. International Journal of Behavioral Medicine, 15(3), 194-200. http://dx.doi.org/10.1080/10705500802222972

Ungar, M. (2013). Resilience, Trauma, Context, and Culture. Trauma Violence Abuse, 14(3), 255-66. https//doi: 10.1177/1524838013487805.

Timmerman, M. E. \& Lorenzo-Seva, U. (2011). Dimensionality Assessment of Ordered Polytomous Items with Parallel Analysis. Psychological Methods, 16, 209-220. https://doi.org/10.1037/a0023353.

Vázquez, A. J., García-Bóveda, R., \&amp; Vázquez-Morejón, R. (2004). Escala de autoestima de Rosenberg: fiabilidad y validez en población clínica española [Rosenberg self-esteem scale: reliability and validity in the Spanish clinical population]. Apuntes de psicología, 22(2), 247-255.

Windle, G., Bennett, K. M., \& Noyes, J. (2011). A methodological review of resilience measurement scales. Health Quality of Life Outcomes, 9(8), 1-18. https://doi.org/10.1186/1477-7525-9-8 